\title{
Sugars metabolism and ethanol production by different yeast strains from coffee industry wastes hydrolysates
}

\author{
Solange I. Mussatto ${ }^{\mathrm{a}, *}$, Ercília M.S. Machado ${ }^{\mathrm{a}}$, Lívia M. Carneiro ${ }^{\mathrm{b}}$, José A. Teixeira ${ }^{\mathrm{a}}$ \\ ${ }^{a}$ Institute for Biotechnology and Bioengineering (IBB), Centre of Biological Engineering, University of Minho, Campus Gualtar, 4710-057 Braga, Portugal \\ ${ }^{\mathrm{b}}$ Department of Biotechnology, Engineering College of Lorena, University of São Paulo, Estrada Municipal do Campinho s/n, $12602-810$ Lorena/SP, Brazil
}

\section{A R T I C L E I N F O}

\section{Article history:}

Received 2 March 2011

Received in revised form 19 July 2011

Accepted 12 August 2011

Available online 17 September 2011

\section{Keywords:}

Coffee silverskin

Spent coffee grounds

Ethanol

Saccharomyces cerevisiae

Pichia stipitis

Kluyveromyces fragilis

\begin{abstract}
A B S T R A C T
Significant amounts of wastes are generated by the coffee industry, among of which, coffee silverskin (CS) and spent coffee grounds (SCG) are the most abundantly generated during the beans roasting and instant coffee preparation, respectively. This study evaluated the sugars metabolism and production of ethanol by three different yeast strains (Saccharomyces cerevisiae, Pichia stipitis and Kluyveromyces fragilis) when cultivated in sugar rich hydrolysates produced by acid hydrolysis of CS and SCG. S. cerevisiae provided the best ethanol production from SCG hydrolysate ( $11.7 \mathrm{~g} / \mathrm{l}, 50.2 \%$ efficiency). On the other hand, insignificant $(\leqslant 1.0 \mathrm{~g} / \mathrm{l})$ ethanol production was obtained from CS hydrolysate, for all the evaluated yeast strains, probably due to the low sugars concentration present in this medium (approx. $22 \mathrm{~g} / \mathrm{l}$ ). It was concluded that it is possible to reuse SCG as raw material for ethanol production, which is of great interest for the production of this biofuel, as well as to add value to this agro-industrial waste. CS hydrolysate, in the way that is produced, was not a suitable fermentation medium for ethanol production; however, the hydrolysate concentration for the sugars content increase previous the use as fermentation medium could be an alternative to overcome this problem.
\end{abstract}

(c) 2011 Elsevier Ltd. All rights reserved.

\section{Introduction}

Significant amounts of wastes are generated by the coffee industry, among of which, coffee silverskin (CS, the tegument that cover each coffee bean) is the main waste generated during the beans roasting [1]; and spent coffee grounds (SCG, the solid residue obtained during the treatment of coffee powder with hot water or steam) is the main waste generated during the instant coffee preparation [2], with a worldwide annual production of $6,000,000$ tons [3]. Although these wastes are generated in large quantities every year, few studies have been addressed to their reuse. In some countries, CS has been used as soil fertilizer or as fuel [4]; while SCG is normally released to the environment or used as fuel in industrial boilers of the same industry, due to its high calorific power (approx. $5000 \mathrm{kcal} / \mathrm{kg}$ ) [5]. Some studies have evaluated the SCG use as animal feed, however, the high lignin content $(\approx 25 \% \mathrm{w} / \mathrm{w})$ of this material was considered a limiting factor for this application [6]. Based on these facts and considering the large amount of coffee wastes generated every year, comes the need to find alternatives for CS and SCG reuse, both from economical and environmental view points.

\footnotetext{
* Corresponding author. Tel.: +351 253604424; fax: +351 253604429.

E-mail addresses: solange@deb.uminho.pt, solangemussatto@hotmail.com (S.I. Mussatto).
}

The ethanol production by fermentation has received large importance in the last few years due to its increased demand as fuel and complement to gasoline [7,8]. In addition, the ethanol use as fuel is also of interest because it reduces the dependence on oil; the air pollution and climate change caused by emissions of carbon dioxide [9]. Ethanol production by fermentation of agro-industrial wastes is very attractive because of their low cost and abundance, and non-competition with foodstuffs [10]. Some recent studies report that CS and SCG wastes are rich in sugars $[2,11]$, which could be extracted and used as substrate in fermentation processes.

There is not any published study on the production of ethanol from coffee industry wastes. For this reason, and considering the variety of sugars present in these wastes [2,11], it is of importance to find a microorganism able to consume these sugars and convert them to ethanol. Saccharomyces cerevisiae is the microorganism most often used for ethanol production, due to its ability to grow in media containing high sugars concentration and its high ethanol yield. However, this yeast only ferments hexoses, being unable to produce ethanol from pentoses such as xylose [12]. Xylose is usually obtained during the hydrolysis of the hemicellulose fraction of agricultural wastes, and its bioconversion is an important step in the reuse of these materials $[13,14]$. Yeast strains from the genera Pichia, Candida, Schizosaccharomyces and Pachysolen, the filamentous fungi Paecilomyces, Mucor, Monilia and Fusarium, and bacteria Clostridium, Bacillus, Bacteroides, Thermoanaerobacter, 
and Erwinia, have been reported as able to produce ethanol from pentoses $[15,16]$. In our recent studies on ethanol production from lignocellulosic hydrolysates, Pichia stipitis (NRRL-Y-7124), S. cerevisiae (RL-11), and Kluyveromyces fragilis (Kf1) were demonstrated to be good ethanol producers from different sugars sources $[17,18]$.

The objective of this work was to investigate the possibility of using coffee industry wastes (CS and SCG) as raw materials for ethanol production by fermentation. Since the hydrolysates produced from these wastes contain a mixture of hexose and pentose sugars, the ability of three different yeast strains ( $P$. stipitis NRRL-Y-7124, S. cerevisiae RL-11, and $K$. fragilis Kf1) to metabolize their sugars and convert them to ethanol was evaluated and compared.

\section{Material and methods}

\subsection{Raw material}

Coffee silverskin (CS) and spent coffee grounds (SCG) were supplied by NovaDelta - Comércio e Indústria de Cafés, Lda (Campo Maior, Portugal). As soon as obtained, the materials were dried at $60{ }^{\circ} \mathrm{C}$ to $10 \%$ moisture content to be stored. Chemical composition of CS consisted of $(\mathrm{g} / 100 \mathrm{~g})$ : glucan (17.8), xylan (4.7), arabinan (2.0), galactan (3.8), mannan (2.6), protein (16.2), lignin (30.2), ashes (4.7), acetyl groups (3.0), and extractives (15.0); while SCG contained glucan (8.6), arabinan (1.7), galactan (13.8), mannan (21.2), protein (13.6), lignin (32.1), ashes (1.6), acetyl groups (2.2), and extractives (5.2).

\subsection{Hydrolysates preparation}

The reaction conditions used for CS and SCG hydrolysis were optimized in previous studies, one of which has already been published [11]. Reaction conditions consisted in using a sulfuric acid solution ( $100 \mathrm{mg} \mathrm{H}_{2} \mathrm{SO}_{4} / \mathrm{g}$ dry matter) in a liquid/solid ratio of $10 \mathrm{~g} / \mathrm{g}$, at $163{ }^{\circ} \mathrm{C}$ during $45 \mathrm{~min}$, for SCG; and in a liquid/solid ratio of $14 \mathrm{~g} / \mathrm{g}$, at $170^{\circ} \mathrm{C}$ during $45 \mathrm{~min}$, for CS. The reactions were performed in $200 \mathrm{ml}$ stainless steel reactors, containing $70 \mathrm{ml}$ of reaction medium. Under the required temperature, the dully-covered reactors (filled with CS or SCG, and the acid solution) were introduced into a silicone oil bath, were they were maintained during the desired time. At the end of the reaction, the reactors were immediately cooled in ice bath. The hydrolysates were then separated from the solid residue by centrifugation (6000 rpm, $15 \mathrm{~min}$ ), and characterized regarding the concentration of sugars (glucose, xylose, arabinose, mannose, and galactose) and toxic compounds (furfural, hydroxymethylfurfural, acetic acid, and phenolic compounds) by HPLC. To be used as fermentation medium, the hydrolysates had their pHs adjusted to 5.5 by addition of $\mathrm{NaOH}$ (pellets); the remaining solid residue was removed by centrifugation (6000 rpm, $15 \mathrm{~min}$ ). Sugar losses after this neutralization step were less than $4 \%$.

\subsection{Microorganisms}

Three different yeast strains were evaluated, including P. stipitis (NRRL-Y-7124), S. cerevisiae (RL-11), and K. fragilis (Kf1). $S$. cerevisiae was supplied by University of Lavras (Department of Biology), Brazil. This yeast was selected among other strains due to its high capacity of producing ethanol [19]. K. fragilis was also supplied by University of Lavras (Department of Biology), Brazil, and was isolated from cocoa fermentation. This yeast has been demonstrated to have great ability for ethanol production from cheese whey [17].

\subsection{Inocula and fermentation conditions}

Cultures of the yeasts were maintained at $4{ }^{\circ} \mathrm{C}$ on Petri plates containing malt extract agar medium whose composition consisted in $(\mathrm{g} / \mathrm{l})$ : yeast extract (3.0), malt extract (3.0), peptone (5.0), glucose (10.0), and agar (20.0). For the inoculum preparation, cells of the yeasts grown during $24 \mathrm{~h}$ in the maintenance medium were transferred to $500 \mathrm{ml}$ Erlenmeyer flasks containing $100 \mathrm{ml}$ of culture medium composed of (g/l): glucose (30.0), $\left(\mathrm{NH}_{4}\right)_{2} \mathrm{HPO}_{4}$ (3.0), $\mathrm{MgSO}_{4} \cdot 7 \mathrm{H}_{2} \mathrm{O}$ (1.0), and yeast extract (3.0). Concentrated solutions of each compound were prepared separately and sterilized in an autoclave at $121^{\circ} \mathrm{C}$ for $20 \mathrm{~min}$, with the exception of glucose and yeast extract that were autoclaved at $112{ }^{\circ} \mathrm{C}$ for $15 \mathrm{~min}$. The solutions were aseptically mixed in order to obtain the desired concentration of each nutrient in the culture medium.

The inoculated flasks were incubated in a rotary shaker at $30^{\circ} \mathrm{C}$, $200 \mathrm{rpm}$, for $24 \mathrm{~h}$. After this time, the cells were recovered by centrifugation (5000 rpm, $20 \mathrm{~min}$ ) and resuspended in the fermentation medium. Fermentation assays were performed in $250 \mathrm{ml}$ Erlenmeyer flasks containing $100 \mathrm{ml}$ of fermentation medium (hydrolysates) inoculated with an initial cell concentration of $1 \mathrm{~g} /$ l. The flasks were incubated in a rotary shaker at $30^{\circ} \mathrm{C}, 200 \mathrm{rpm}$ for $48 \mathrm{~h}$. During the experiments, samples were taken for sugars, ethanol and cell growth determinations. All the assays were performed at least in duplicate.

\subsection{Analytical methods}

Microbial growth was determined after drying the samples at $105^{\circ} \mathrm{C}$ to constant weight. Quantification of total phenolic compounds was carried out using the Folin-Ciocalteu method. Total sugars were determined by the dinitrosalicylic (DNS) and anthrone methods.

Ethanol and acetic acid concentrations were determined by high performance liquid chromatography (HPLC) on a Jasco chromatograph equipped with a refractive index detector and a BioRad Aminex HPX-87H $(300 \times 7.8 \mathrm{~mm})$ column at $60{ }^{\circ} \mathrm{C}$, using $0.005 \mathrm{M}$ sulfuric acid as eluent in a flow rate of $0.7 \mathrm{ml} / \mathrm{min}$. Concentration of glucose, xylose, arabinose, mannose and galactose was also determined by HPLC using a refractive index detector, but with a Varian column Metacarb $87 \mathrm{P}(300 \times 7.8 \mathrm{~mm})$ at $80^{\circ} \mathrm{C}$, and ultrapure water as eluent in a flow rate of $0.4 \mathrm{ml} / \mathrm{min}$. Furfural and hydroxymethylfurfural (HMF) were determined by HPLC using a UV detector (at $280 \mathrm{~nm}$ ) and a Nucleosil 120-5 C18 $5 \mu \mathrm{m}$ $(4.6 \times 250 \mathrm{~mm})$ column at room temperature, acetonitrile/water ( $1 / 8$ with $10 \mathrm{~g} / \mathrm{l}$ acetic acid) as the eluent in a flow rate of $0.8 \mathrm{ml} /$ min. In all the cases, a sample volume of $20 \mu \mathrm{l}$ was injected.

The ethanol yield factor $\left(Y_{\mathrm{P} / \mathrm{S}}, \mathrm{g} / \mathrm{g}\right)$ was defined as the ratio between the maximum ethanol concentration $(\mathrm{g} / \mathrm{l})$ and total sugars consumed (g/l). Ethanol volumetric productivity $\left(Q_{p}, g / l \mathrm{~h}\right)$ was calculated as the ratio between the maximum ethanol concentration $(\mathrm{g} / \mathrm{l})$ and the respective fermentation time (h). The efficiency of sugars conversion to ethanol $(\eta$, \%) was determined as the ratio between the obtained $Y_{\mathrm{P} / \mathrm{S}}(\mathrm{g} / \mathrm{g})$ and the theoretical value $(0.51 \mathrm{~g} / \mathrm{g})$ of this parameter [15].

\section{Results and discussion}

\subsection{Hydrolysates composition}

The hydrolysates produced from SCG and CS contained significant total sugar amounts, correspondent to approx. 50 and $20 \mathrm{~g} / \mathrm{l}$, respectively. For both wastes, the hydrolysis process was performed with high efficiency of sugars extraction ( $>85 \%)$, and the different values of sugars concentration in the hydrolysates is a 
consequence of the original content present in each raw material, since SCG is richer in sugars than CS (as can be seen in Section 2.1 ). Besides the release of sugars from the raw materials structures, the hydrolysis process also promoted the release and/or formation of some compounds, namely acetic acid, furfural, hydroxymethylfurfural (HMF) and phenolic compounds, which can be toxic for the microbial metabolism depending on the concentration that they are present in the fermentation medium [20]. Concentration of these toxic compounds in SCG and CS hydrolysates are given in Table 1 . As can be observed in this table, the concentration of furfural and HMF (compounds generated from the degradation of pentose and hexose sugars, respectively) was low $(<1.0 \mathrm{~g} / \mathrm{l})$ demonstrating that the hydrolysis conditions were able to promote a highly efficient sugars extraction with few degradation of the monosaccharides. Acetic acid that is released from the hemicellulose structure was also present in both hydrolysates, but in a slightly higher concentration in CS hydrolysate, that is in agreement with the chemical composition of the wastes, since CS contains more acetyl groups than SCG (3.0 and 2.2\% w/w, respectively). Phenolic compounds were present in similar concentration in both hydrolysates.

It is expected that furfural, HMF and acetic acid, in the concentrations present in SCG and CS hydrolysates, do not cause inhibition in the yeasts metabolism, since several studies report inhibition of the microbial metabolism by concentration values higher than those here found. For example, ethanol production by $P$. stipitis CECT 1922 was not affected by furfural concentrations up to $2 \mathrm{~g} / \mathrm{l}$, neither by acetic acid concentrations up to $6 \mathrm{~g} / \mathrm{l}$; and the simultaneous presence of acetic acid $(1.5 \mathrm{~g} / \mathrm{l})$, formic acid $(0.5 \mathrm{~g} / \mathrm{l})$, and furfural $(1 \mathrm{~g} / \mathrm{l})$ did not affect also the yeast performance in converting xylose and glucose to ethanol [21]. On the other hand, phenolic compounds have been considered the most toxic compounds present in lignocellulosic hydrolysates, being toxic for the microorganism even when present at low concentrations [20]. Several works report the use of detoxification processes previous the hydrolysate use as fermentation medium, to decrease the concentration of toxic compounds to levels not able to affect the microbial metabolism. In the present study, CS and SCG hydrolysates were used as fermentation medium as obtained. The inclusion of an additional step of hydrolysate detoxification was avoided to not increase the costs of ethanol production.

\subsection{Fermentation of SCG hydrolysate}

The total sugars consumption from SCG hydrolysate varied to each evaluated yeast (Fig. 1A). S. cerevisiae consumed faster these compounds than the other strains, with almost total depletion after $24 \mathrm{~h}$ fermentation. $P$. stipitis also consumed practically all the sugars present in the medium, but required a longer fermentation time ( $36 \mathrm{~h}$ ). On the other hand, $K$. fragilis consumed only $22 \%$ of the sugars present in SCG hydrolysate. The difference observed for the three yeasts is related to the variety of sugars present in this medium. SCG hydrolysate contains glucose, arabinose, galactose and mannose sugars; galactose and mannose being the most

Table 1

Concentration of toxic compounds in coffee silverskin (CS) and spent coffee grounds (SCG) hydrolysates.

\begin{tabular}{lll}
\hline Toxic compounds & \multicolumn{2}{l}{ Concentration in the hydrolysate $(\mathrm{g} / \mathrm{l})$} \\
\cline { 2 - 3 } & CS & SCG \\
\hline Acetic acid & $1.10 \pm 0.10$ & $0.80 \pm 0.05$ \\
Furfural & $0.20 \pm 0.06$ & $0.70 \pm 0.03$ \\
HMF & $0.30 \pm 0.04$ & $0.10 \pm 0.01$ \\
Phenolic compounds & $3.70 \pm 0.20$ & $3.50 \pm 0.12$ \\
\hline
\end{tabular}


Fig. 1. Consumption of total sugars (A), galactose (B) and mannose (C) in spent coffee grounds hydrolysate, during the fermentation for ethanol production by different yeast strains.

abundant, accounting for about $77 \%$ of total sugars present [11]. $S$. cerevisiae is a yeast strain with ability to utilize and metabolize hexose sugars such as galactose, mannose and glucose [22]. $P$. stipitis has been reported as able to consume both kinds of sugars: hexoses and pentoses like xylose, for example [23]. K. fragilis is a strain mainly reported as able to consume lactose [24], sugar that was not present in SCG hydrolysate. Glucose was present in low concentration $(0.81 \mathrm{~g} / \mathrm{l})$ in this medium, and was totally consumed by the three yeasts. On the other hand, galactose and mannose 
consumption was clearly different for each yeast strain (Fig. 1B and C). Galactose and mannose consumption by $K$. fragilis was really small, especially when compared with the results observed for the other two yeasts. Mannose consumption was similar for $S$. cerevisiae and P. stipitis; however, S. cerevisiae consumed galactose faster than $P$. stipitis, although both yeasts consumed totally this hexose. Arabinose was not consumed by any of the yeasts, during the considered fermentation time.

As a consequence of the differences in sugars consumption, biomass formation and ethanol production varied to each yeast strain (Fig. 2). All the yeasts strains were able to grow in SCG hydrolysate, but $S$. cerevisiae exhibited the highest and fastest growth results, as result of its higher and faster sugars consumption compared to the other strains. Otherwise, $K$. fragilis had the worst growth results, since it consumed few sugars amount (Fig. 2A). In terms of ethanol production, fermentation with $S$. cerevisiae gave the best results $(11.7 \mathrm{~g} / \mathrm{l})$ (Fig. 2B), followed by the fermentation with. P. stipitis, which produced ethanol concentrations similar to those of $S$. cerevisiae, but needed a longer time to achieve the maximum concentration of this compound. Ethanol production by K. fragilis was low throughout the fermentation time. It is evident by these results that this yeast strain had difficulties in metabolizing the main sugars present in SCG hydrolysate (mannose and galactose), and convert them to ethanol.

Table 2 presents the fermentation parameters obtained during the conversion of SCG hydrolysate by the three yeasts. Note that the ethanol yield factors $\left(Y_{\mathrm{P} / \mathrm{S}}\right)$ were similar for the fermentations performed with $P$. stipitis and $S$. cerevisiae, which shows that both
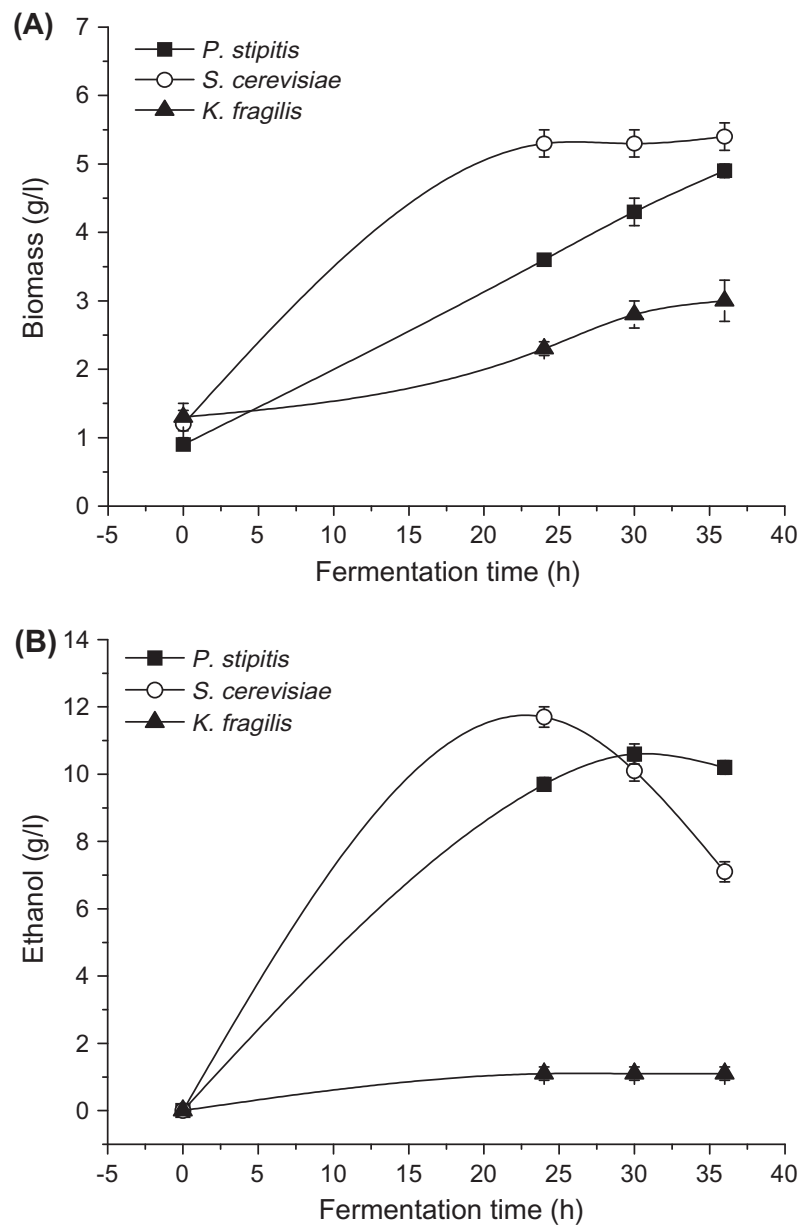

Fig. 2. Biomass and ethanol production during the fermentation of spent coffee grounds hydrolysate by different yeast strains.
Table 2

Fermentation parameters obtained during the conversion of spent coffee grounds hydrolysate to ethanol by different yeast strains.

\begin{tabular}{lllll}
\hline Yeast & $Y_{\mathrm{P} / \mathrm{S}}(\mathrm{g} / \mathrm{g})$ & $Q_{\mathrm{P}}(\mathrm{g} / \mathrm{l} \mathrm{h})$ & $\eta(\%)$ & Time $(\mathrm{h})$ \\
\hline Pichia stipitis & $0.26 \pm 0.01$ & $0.35 \pm 0.01$ & $51.9 \pm 2.3$ & 30 \\
Saccharomyces cerevisiae & $0.26 \pm 0.02$ & $0.49 \pm 0.01$ & $50.2 \pm 3.1$ & 24 \\
Kluyveromyces fragilis & $0.13 \pm 0.02$ & $0.05 \pm 0.01$ & $25.5 \pm 3.3$ & 24 \\
\hline
\end{tabular}

$Y_{\mathrm{P} / \mathrm{S}}=$ ethanol yield factor; $Q_{\mathrm{P}}=$ ethanol productivity; $\eta=$ ethanol efficiency.

yeasts had the same ability to convert the sugars to ethanol. As a consequence, both yeasts proportioned similar results of efficiency $(\eta)$. However, ethanol productivity $\left(Q_{P}\right)$ was higher for $S$. cerevisiae than for $P$. stipitis, suggesting that $S$. cerevisiae had greater ability for ethanol production from sugars present in SCG hydrolysate. $K$. fragilis yielded an $Y_{\mathrm{P} / \mathrm{S}}$ value correspondent to half the value obtained for the other yeasts, and a very low $Q_{p}$, as a result of the low ethanol concentration formed during the fermentation (about $1.1 \mathrm{~g} / \mathrm{l})$.

The maximum values of $Y_{\mathrm{P} / \mathrm{S}}(0.26 \mathrm{~g} / \mathrm{g})$ and $Q_{\mathrm{P}}(0.49 \mathrm{~g} / \mathrm{l} \mathrm{h})$ obtained in this study are comparable or even better than others found during the ethanol production from hemicellulosic hydrolysates obtained from different raw materials. For example, bioconversion of brewer's spent grain hemicellulosic hydrolysate to ethanol by $P$. stipitis NRRL-Y-7124 yielded an $Y_{\mathrm{P} / \mathrm{S}}$ of $0.34 \mathrm{~g} / \mathrm{g}$ [25]; the ethanol production by fermentation of sunflower seed hull hydrolysate, also using $P$. stipitis NRRL-Y-7124, gave $Y_{\mathrm{P} / \mathrm{S}}$ and $Q_{\mathrm{P}}$ values of $0.32 \mathrm{~g} / \mathrm{g}$ and $0.065 \mathrm{~g} / \mathrm{l} \mathrm{h}$, respectively [26]; and the fermentation of sugarcane bagasse hemicellulosic hydrolysate by Scheffersomyces stipitis UFMG-IMH 43.2 yielded $Y_{\mathrm{P} / \mathrm{S}}$ of $0.19 \mathrm{~g} / \mathrm{g}$ and $Q_{p}$ of $0.13 \mathrm{~g} / \mathrm{l} \mathrm{h}$ [27]. When compared to the fermentation results obtained from these raw materials, it can be concluded that SCG hydrolysate has great potential for use as fermentation medium for ethanol production. Additionally, the sugars content present in the original raw material is also an important factor to support this conclusion, because high ethanol production may be achieved if high sugars content is available for fermentation. In this sense, sugars composition in SCG $(45.3 \% \mathrm{w} / \mathrm{w})$ [11], is well comparable to the sugars composition of other raw materials, such as brewer's spent grain [28], corn fiber [29], and corn stover [30], for example.

It is worth mentioning that this is a first study on ethanol production from SCG hydrolysate, and the results here obtained may be improved if the best operational conditions to perform this process (for example: initial substrate concentration, $\mathrm{pH}$, addition of nutrients, oxygen availability, and others) are established. Additionally, studies about the influence of the inhibitory compounds (mainly the phenolic compounds) present in this hydrolysate on yeast metabolism could be useful to verify if the yeast performance is improved when using the detoxified hydrolysate as fermentation medium.

\subsection{Fermentation of CS hydrolysate}

Unlike the observed in the fermentation of SCG hydrolysate, where $S$. cerevisiae consumed the highest sugar amount and faster than the other yeast strains, $P$. stipitis was the yeast responsible for the quickest and highest sugar consumption from CS hydrolysate (Fig. 3A). This fact is also related to the chemical composition of this medium. CS hydrolysate contains xylose, pentose sugar that was not present in SCG hydrolysate. Xylose account for 20\% of total sugars present in this medium and is metabolized by $P$. stipitis but not by $S$. cerevisiae and $K$. fragilis [22-24], explaining the lower intake of sugars observed for these other two yeasts.

In terms of cell growth (Fig. 3B) K. fragilis exhibited the highest values of biomass from CS hydrolysate, while the lowest values were obtained for $S$. cerevisiae. Note that initially, the biomass 

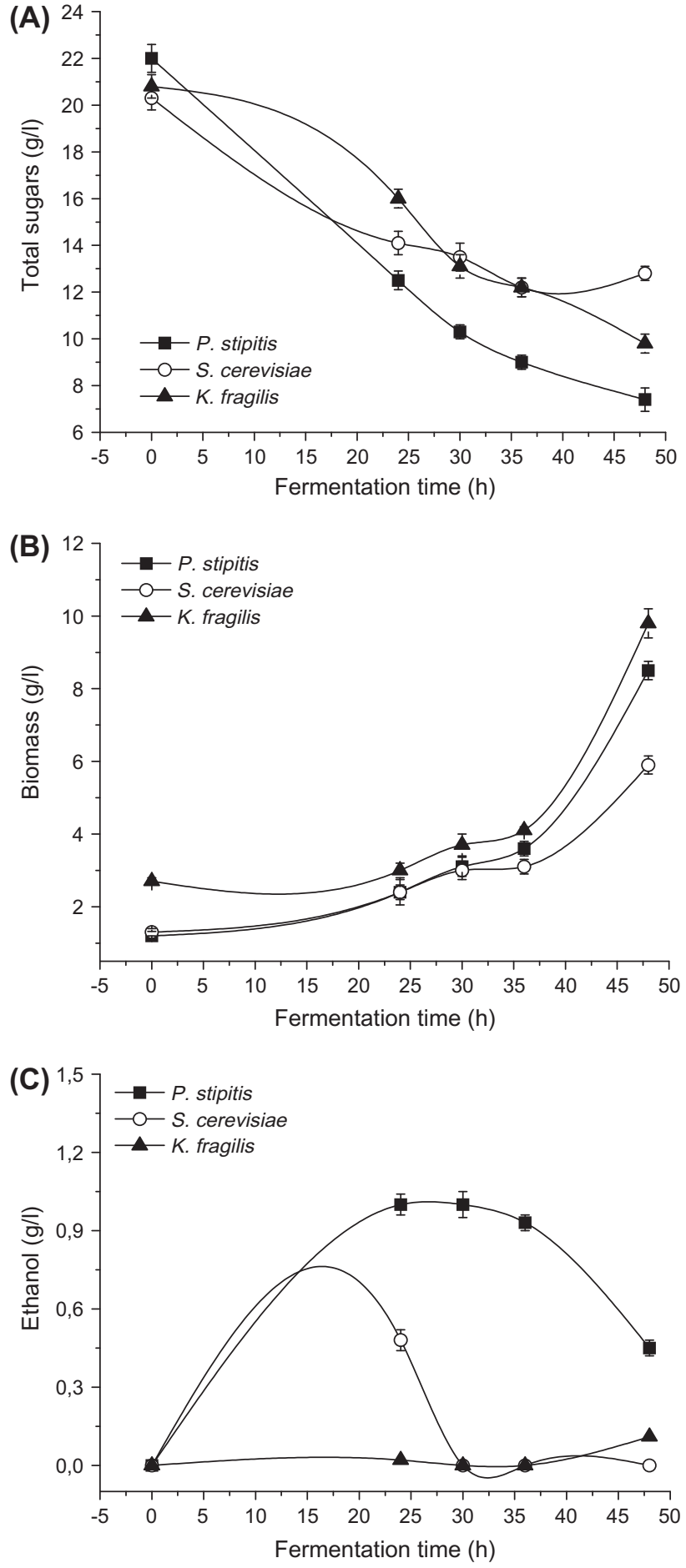

Fig. 3. Total sugars consumption (A), biomass (B) and ethanol production (C) during the fermentation of coffee silverskin hydrolysate by different yeast strains.

formation was similar for $P$. stipitis and S. cerevisiae, however, after $30 \mathrm{~h}$ of fermentation $P$. stipitis increased its biomass in larger extends than $S$. cerevisiae, probably due to the consumption of pentose sugars, which are not metabolized by $S$. cerevisiae, as mentioned before. The highest values of biomass obtained with $K$. fragilis are related to the no production of ethanol by this microorganism (Fig. 3C), as a consequence, the yeast would have used the entire consumed carbon source only for the cell growth.

Among the studied strains, $P$. stipitis produced the highest ethanol amount from CS hydrolysate. However, the ethanol concentration values obtained in all these fermentations were very low
Table 3

Fermentation parameters obtained during the conversion of coffee silverskin hydrolysate to ethanol by different yeast strains.

\begin{tabular}{lllll}
\hline Yeast & $Y_{\mathrm{P} / \mathrm{S}}(\mathrm{g} / \mathrm{g})$ & $\mathrm{Q}_{\mathrm{P}}(\mathrm{g} / \mathrm{l} \mathrm{h})$ & $\eta(\%)$ & Time $(\mathrm{h})$ \\
\hline Pichia stipitis & $0.11 \pm 0.02$ & $0.04 \pm 0.01$ & $21.0 \pm 3.0$ & 24 \\
Saccharomyces cerevisiae & $0.13 \pm 0.03$ & $0.02 \pm 0.01$ & $24.9 \pm 5.1$ & 24 \\
Kluyveromyces fragilis & $0.01 \pm 0.00$ & $0.00 \pm 0.00$ & $2.2 \pm 0.3$ & 48 \\
\hline
\end{tabular}

$Y_{\mathrm{P} / \mathrm{S}}=$ ethanol yield factor; $Q_{\mathrm{P}}=$ ethanol productivity; $\eta=$ ethanol efficiency.

$(\leqslant 1.0 \mathrm{~g} / \mathrm{l})$ due to the low initial sugars concentration in CS hydrolysate $(\approx 22 \mathrm{~g} / \mathrm{l})$. Since part of the carbon source is used by the microorganism for the cell growth, few amounts would have been available for use on product formation. Table 3 shows the fermentation parameters obtained during the conversion of CS hydrolysate by the three yeast strains. Note that the values of ethanol yield factor $\left(Y_{\mathrm{P} / \mathrm{S}}\right)$ and productivity $\left(Q_{\mathrm{P}}\right)$ were low, even for $P$. stipitis that provided the highest ethanol concentration. In fact, the initial substrate concentration in the fermentation medium is directly related to the product formation, and influences the $Y_{\mathrm{P} / \mathrm{S}}$ and $Q_{\mathrm{P}}$ values, as a consequence $[18,31,32]$. The initial sugars concentration in SCG hydrolysate $(\approx 54 \mathrm{~g} / \mathrm{l})$ was twice the initial concentration in CS hydrolysate, which certainly had a positive effect on the fermentation results obtained. It has been demonstrated in other bioconversion studies that the yield and productivity of the process are improved when the initial sugars concentration is increased, of course, up to a certain limit $[18,31,32]$. Establishing the initial substrate concentration to be used in a fermentation process is important to attain elevated product formation $[18,31,32]$. Therefore, a possible alternative to improve the low ethanol production results obtained from CS hydrolysate could be to submit it to a concentration process previous the use as fermentation medium, to increase the sugars concentration. This will be the focus of our future studies.

\section{Conclusions}

SCG is an agro-industrial waste of large potential for use as raw material for ethanol production, since interesting results of ethanol yield $\left(Y_{\mathrm{P} / \mathrm{S}}=0.26 \mathrm{~g} / \mathrm{g}\right)$, productivity $\left(Q_{\mathrm{P}}=0.49 \mathrm{~g} / \mathrm{l} \mathrm{h}\right)$ and efficiency $(\eta=50.2 \%)$ were obtained when the sugar-rich hydrolysate produced from this material was used as fermentation medium (without any detoxification procedure) by $S$. cerevisiae. Such results could be even improved by establishing the operational conditions that maximize the product formation. On the other hand, fermentation of CS hydrolysate did not yield significant ethanol amounts, probably due to the low concentration of sugars in this hydrolysate, which were used primarily for the microorganisms' growth. However, this hydrolysate acted as an efficient medium for the yeasts' growth, suggesting that it may also be of interest for use in fermentation processes. Concentrating the CS hydrolysate previous its use as fermentation medium could be an alternative to improve the ethanol production results.

\section{Acknowledgement}

The authors are grateful to NovaDelta - Comércio e Indústria de Cafés, Lda (Campo Maior, Portugal) for providing the coffee wastes samples.

\section{References}

[1] Napolitano A, Fogliano V, Tafuri A, Ritieni A. Natural occurrence of ochratoxin A and antioxidant activities of green and roasted coffees and corresponding byproducts. J Agric Food Chem 2007;55:10499-504.

[2] Mussatto SI, Machado EMS, Martins S, Teixeira JA. Production, composition and application of coffee and its industrial residues. Food Bioprocess Tech 2011;4:661-72. 
[3] Tokimoto T, Kawasaki N, Nakamura T, Akutagawa J, Tanada S. Removal of lead ions in drinking water by coffee grounds as vegetable biomass. J Colloid Interf Sci 2005;281:56-61.

[4] Saenger M, Hartge E-U, Werther J, Ogada T, Siagi Z. Combustion of coffee husks. Renew Energ 2001:23:103-21.

[5] Silva MA, Nebra SA, Machado Silva MJ, Sanchez CG. The use of biomass residues in the Brazilian soluble coffee industry. Biomass Bioenerg 1998;14: 457-67.

[6] Cruz GM. Resíduos de cultura e indústria. Informe Agropecuário 1983;9:32-7.

[7] Yan J, Lin T. Biofuels in Asia. Appl Energ 2009;86:S1-S10.

[8] Balat M, Balat H. Recent trends in global production and utilization of bioethanol fuel. Appl Energ 2009;86:2273-82.

[9] Demirbas A. Bioethanol from cellulosic materials: a renewable motor fuel from biomass. Energ Source 2005;27:327-37.

[10] Mussatto SI, Dragone G, Guimarães PMR, Silva JPA, Carneiro LM, Roberto IC et al. Technological trends, global market, and challenges of bio-ethanol production. Biotechnol Adv 2010;28:817-30.

[11] Mussatto SI, Carneiro LM, Silva JPA, Roberto IC, Teixeira JA. A study on chemical constituents and sugars extraction from spent coffee grounds. Carbohyd Polym 2011;83:368-74.

[12] Kumar A, Singh LK, Ghosh S. Bioconversion of lignocellulosic fraction of waterhyacinth (Eichhornia crassipes) hemicellulose acid hydrolysate to ethanol by Pichia stipitis. Bioresource Technol 2009;100:3293-7.

[13] Nakamura Y, Sawada T, Inoue E. Mathematical model for ethanol production from mixed sugars by Pichia stipitis. J Chem Technol Biot 2001;76:586-92.

[14] Guo GL, Chen WH, Men LC, Hwang WS. Characterization of dilute acid pretreatment of silvergrass for ethanol production. Bioresource Technol 2008;14:6046-53.

[15] Millati R, Edebo L, Taherzadeh MJ. Performance of Rhizomucor and Mucor in ethanol production from glucose, xylose, and wood hydrolyzates. Enzyme Microb Tech 2005;35:294-300.

[16] Hahn-Hagerdal B, Jeppsson H, Skoog K, Prior BA. Biochemistry and physiology of xylose fermentation by yeasts. Enzyme Microb Tech 1994;16:933-42.

[17] Dragone G, Mussatto SI, Almeida e Silva JB, Teixeira JA. Optimal fermentation conditions for maximizing the ethanol production by Kluyveromyces fragilis from cheese whey powder. Biomass Bioenerg 2011;35:1977-82.

[18] Silva JPA, Mussatto SI, Roberto IC. The influence of initial xylose concentration, agitation, and aeration on ethanol production by Pichia stipitis from rice straw hemicellulosic hydrolysate. Appl Biochem Biotechnol 2010;162:1306-15.
[19] Dias DR, Schwan RF, Lima LCO. Metodologia para elaboração de fermentado de cajá (Spondias mombin L.). Ciênc Tecnol Aliment 2003;23:342-50.

[20] Mussatto SI, Roberto IC. Alternatives for detoxification of diluted-acid lignocellulosic hydrolyzates for use in fermentative processes - a review. Bioresource Technol 2004;93:1-10.

[21] Diaz MJ, Ruiz E, Romero I, Cara C, Moya M, Castro E. Inhibition of Pichia stipitis fermentation of hydrolysates from olive tree cuttings. World J Microbio Biotechnol 2009;25:891-9.

[22] Barnett JA. The utilization of sugars by yeasts. Adv Carbohyd Chem Bi 1976;32:125-234

[23] Sánchez S, Bravo V, Castro E, Moya AJ, Camacho F. The fermentation of mixtures of D-glucose and D-xylose by Candida shehatae, Pichia stipitis or Pachysolen tannophilus to produce ethanol. J Chem Technol Biot 2002;77: 641-8.

24] Izaguirre ME, Castillo FJ. Selection of lactose-fermenting yeast for ethano production from whey. Biotechnol Lett 1982;4:257-62.

[25] Brito RA, Roberto IC. Utilização do hidrolisado hemicelulósico do bagaço de malte para obtenção de bioetanol. In: $16^{\circ}$ Simpósio Internacional de Iniciação Científica da USP. São Paulo: Book of Abstracts; 2008.

[26] Telli-Okur M, Eken-Saraçoglu N. Fermentation of sunflower seed hull hydrolysate to ethanol by Pichia stipitis. Bioresource Technol 2007;99:2162-9.

[27] Ferreira AD, Mussatto SI, Cadete RM, Rosa CA, Silva SS. Ethanol production by new pentose-fermenting yeast strain, Scheffersomyces stipitis UFMG-IMH 43.2, isolated from the Brazilian forest. Yeast 2011;28:547-54.

[28] Mussatto SI, Roberto IC. Chemical characterization and liberation of pentose sugars from brewer's spent grain. J Chem Technol Biotechnol 2006:81:268-74.

[29] Gáspár M, Kálmán G, Réczey K. Corn fiber as a raw material for hemicellulose and ethanol production. Process Biochem 2007;42:1135-9.

[30] Weiss ND, Farmer JD, Schell DJ. Impact of corn stover composition on hemicellulose conversion during dilute acid pretreatment and enzymatic cellulose digestibility of the pretreated solids. Bioresource Technol 2010;101: 674-8.

31] Mussatto SI, Roberto IC. Establishment of the optimum initial xylose concentration and nutritional supplementation of brewer's spent grain hydrolysate for xylitol production by Candida guilliermondii. Process Biochem 2008;43:540-6.

[32] Parajó JC, Domínguez H, Dominguez JM. Biotechnological production of xylitol 2. Operation in culture media made with commercial sugars. Bioresource Technol 1998;65:203-12. 